\title{
Risk of adjacent-segment disease requiring surgery after short lumbar fusion: results of the French Spine Surgery Society Series
}

\author{
Caroline Scemama, MD, ${ }^{1}$ Baptiste Magrino, MD, ${ }^{1}$ Philippe Gillet, MD, PhD, ${ }^{2}$ and Pierre Guigui, MD' \\ 1Department of Reconstructive and Orthopaedic Surgery, Université René Descartes, European Hospital Georges Pompidou \\ (AP-HP), Paris, France; and 2Orthopaedic Department, University Hospital, Liege, Belgium
}

\begin{abstract}
OBJECTIVE Adjacent-segment disease (ASD) is an increasingly problematic complication following lumbar fusion surgery. The purpose of the current study was to determine the risk of ASD requiring surgical treatment after short lumbar or lumbosacral fusion. Primary spinal disease and surgical factors associated with an increased risk of revision were also investigated.

METHODS This was a retrospective cohort study using the French Spine Surgery Society clinical data that included 3338 patients, with an average follow-up duration of 7 years (range 4-10 years). Clinical ASD requiring surgery was the principal judgment criterion; the length of follow-up time and initial spinal disease were also recorded. Kaplan-Meier survival analysis was performed. The correlation between primary spinal disease and surgery with an increased risk of revision was investigated.
\end{abstract}

RESULTS During the follow-up period, 186 patients required revision surgery for ASD (5.6\%). The predicted risk of ASD requiring revision surgery was $1.7 \%(95 \% \mathrm{Cl} 1.3 \%-2.2 \%)$ at 2 years, $3.8 \%(95 \% \mathrm{Cl} 4.9 \%-6.7 \%)$ at 4 years, $5.7 \%(95 \%$ $\mathrm{Cl} 4.9 \%-6.7 \%)$ at 6 years, and $9 \%(95 \% \mathrm{Cl} 8.7 \%-10.6 \%)$ at 8 years. Initial spinal disease affected the risk of ASD requiring surgery $(p=0.0003)$. The highest risk was observed for degenerative spondylolisthesis.

CONCLUSIONS ASD requiring revision surgery was predicted in $5.6 \%$ of patients 7 years after index short lumbar spinal fusion in the French Spine Surgery Society retrospective series. An increased risk of ASD requiring revision surgery associated with initial spinal disease showed the significance of the influence of natural degenerative history on adjacent-segment pathology.

http://thejns.org/doi/abs/10.3171/2015.11.SPINE15700

KEY WORDS adjacent segment disease; revision surgery; lumbar fusion surgery; risk factors

$\mathrm{S}$ PINAL fusion has become a standard of care for numerous pathological conditions of the human spine. This surgery eliminates painful motion and allows decompression of the neural elements without further destabilizing the spine. In the US, the annual incidence of spinal fusions has increased more than $600 \%$ between the 1990s and 2011. Currently, about 450,000 spinal fusion surgeries are performed each year in the US. ${ }^{4}$ However, spinal fusion increases the stress on the nonoperated adjacent segments, and in the long term, patients are at risk for developing a common complication called adjacentsegment disease (ASD). ${ }^{9}$

ASD has been defined as the presentation of a new symptom referable to an adjacent level after patients have undergone successful surgical treatment of a spinal problem at an index level. At 10 years after surgery, about $25 \%$ of patients having undergone short lumbar fusion will develop ASD. ${ }^{18}$ In prognostic studies, age greater than 60 years, preexisting facet or disc degeneration in the nonoperated segments, multilevel fusions, fusions not including the L5-S1 level, and laminectomy performed adjacent to a fusion have been reported to be associated with a higher risk of developing an adjacent-segment degeneration. . $^{13,20}$ However, clinical and radiological symptoms of adjacentsegment degeneration do not always warrant an operation. ${ }^{7}$

Indeed, because of comorbidity, patient preferences and

ABBREVIATIONS ALIF = anterior lumbar interbody fusion; $A S D=$ adjacent-segment disease; $C I=$ confidence interval; DD = degenerative discopathy; DS = degenerative stenosis; DSPL = degenerative spondylolisthesis; SSPL = spondylolithic spondylolisthesis.

SUBMITTED June 15, 2015. ACCEPTED November 16, 2015.

INCLUDE WHEN CITING Published online March 11, 2016; DOI: 10.3171/2015.11.SPINE15700. 
surgeon reluctance, or effective medical treatment, clinical or radiographic adjacent-segment degeneration do not always warrant revision surgery. ${ }^{3,8,15,16}$ Some studies have tried to identify variables associated with the risk of revision surgery, but the sample size was small. ${ }^{17}$ In others, the number of predictors investigated was limited ${ }^{14}$ or limited to the patient or the type of surgery performed. ${ }^{15,18}$ Because of these limitations, we decided to conduct a large multicenter cohort study to identify variables associated with the risk of revision surgery.

We conducted a retrospective cohort prediction model study to seek variables associated with the development of ASD in patients undergoing short lumbar or lumbosacral fusion.

\section{Methods \\ Data Source}

This was a multicenter retrospective study including 27 centers through the Société Française de Chirurgie du Rachis (French Society for Spine Surgery). All centers are tertiary care centers and specialize in spine surgery. They are widely distributed geographically across France. Accrual dates were from January 2000 to January 2005; end of follow-up was April 2010.

\section{Participants and Treatment}

Patients were included if they had undergone a short (s 3 levels, between L-3 and S-1) lumbar or lumbosacral fusion for a degenerative condition during the study period (2000-2005). Patients were excluded if the index surgery was performed for a trauma or a tumor; if they had a history of infection; or if they had undergone previous spinal surgery. No selection was based on the surgical treatment received for short lumbar or lumbosacral fusion. The initial treatment included posterolateral fusion without instrumentation, posterolateral fusion with instrumentation, anterior lumbar interbody fusion (ALIF), posterior circumferential fusion, and 2-stage circumferential fusion.

\section{Outcome Variable}

The outcome that was predicted was revision surgery for ASD. Patients were offered revision surgery if they had radiculopathy or low-back pain, had been offered medical treatment including local steroid injections when relevant and physiotherapy, and had radiological signs of ASD. The outcome was assessed both clinically and by imaging studies (radiographs, and MRI and CT scans when relevant) on an annual basis. Ultimately, the decision for revision surgery was shared between the surgeon and the patient.

\section{Predictor Variables}

Predictors included age (linear), sex (binary: male or female), initial spinal disease (categorical: degenerative discopathy [DD], degenerative stenosis [DS], degenerative spondylolisthesis [DSPL], spondylolithic spondylolisthesis [SSPL]), surgical fusion technique (categorical: posterolateral fusion without instrumentation, posterolateral fusion with instrumentation, ALIF, posterior circumferential fusion, and 2-stage circumferential posterior circumferential fusion); number of levels fused (continuous); included the
S-1 level in the fusion (binary: yes or no); if a laminectomy was associated (binary: yes or no); and if a laminectomy was performed, whether it was extended above the most proximal fused level (binary: yes or no). All predictors were assessed at the time of surgery by clinical or imaging studies (radiographs, and MRI and CT scans if relevant).

\section{Statistical Analysis}

The outcome of interest was the cumulative probability of revision surgery for ASD. Estimations and 95\% confidence intervals (CIs) were computed with the KaplanMeier function. ${ }^{11}$ Cox proportional hazard models were built to assess the effect of relevant predictors. Predictors were assessed first in univariate models, and those with a substantial effect on the outcome of interest were then fitted into a multivariate model. All tests were bilateral at the 0.05 level and were based on the log-rank test. Unless specified otherwise, the words "risk" and "hazard" refer to the cause-specific hazard. No study sample size was computed a priori: all eligible patients over the study period were considered for inclusion. No imputation method was used to deal with missing data. Two post hoc analyses were conducted: first we compared the proportion of patients with and without the S-1 level fused in the DSPL to explain discrepancies between uni- and multivariate analyses. Second, we compared the characteristics of patients with more than 4 years of follow-up with those having 4 years or less of follow-up to look for an attrition bias. All analyses were performed using commercial software (Stata, version 11.0) and $\mathrm{R}$ (version 3.1.3., $\mathrm{R}$ Core team).

\section{Results}

\section{Participants}

Included in the study were 3338 patients who met the inclusion criteria. The mean follow-up duration was 7 years (range $4-10$ years). The mean age at the time of initial surgery was $51.2 \pm 14$ years, and the male to female ratio was 0.75 (1430 men and 1908 women). Short fusion was conducted in 1374 (41.3\%) patients for DSPL. The main surgical technique was posterolateral fusion with instrumentation in 2091 patients (62.6\%); 2454 patients (73.5\%) had only 1 level fused; the S-1 level was included in the fusion in 1658 patients (49.7\%). A laminectomy was performed in 2703 patients (81\%), and it was extended above the fusion in $8.6 \%$ (Table 1).

During follow-up, 186 (5.6\%) patients underwent revision surgery for ASD. Figure 1 shows survival probability of not having revision surgery for ASD over time. The cumulative incidence of revision for ASD was $1.7 \%(95 \%$ CI $1.3 \%-2.2 \%)$ at 2 years, $3.8 \%(95 \%$ CI $4.9 \%-6.7 \%)$ at 4 years, $5.7 \%(95 \% \mathrm{CI} 4.9 \%-6.7 \%)$ at 6 years, and $9 \%$ (95\% CI 8.7\%-10.6\%) at 8 years (Fig. 1). The main reason for revision surgery for ASD was stenosis in 124 patients $(66.7 \%)$, which was associated with a spondylolisthesis above the fusion in 50 patients $(26.9 \%)$. Revision surgery for another reason was needed in 99 patients $(3.1 \%)$, and the main reason was pseudarthrosis in 50 patients $(50.5 \%)$.

\section{Predictors}

Three variables were significantly associated with re- 
TABLE 1. Demographic and surgical data (3338 patients)

\begin{tabular}{|c|c|}
\hline Variable & Value (\%) \\
\hline Mean age $\pm S D$ (yrs) & $51.6 \pm 14.5$ \\
\hline \multicolumn{2}{|l|}{ Sex } \\
\hline Female & $1908(57.1)$ \\
\hline Male & $1430(42.9)$ \\
\hline \multicolumn{2}{|l|}{ Initial spinal disease } \\
\hline DD & $654(19.6)$ \\
\hline DS & $375(11.2)$ \\
\hline DSPL & $1374(41.3)$ \\
\hline SSPL & $726(21.7)$ \\
\hline Other & $209(6.2)$ \\
\hline \multicolumn{2}{|l|}{ Fusion type } \\
\hline Posterolateral fusion & $2091(62.6)$ \\
\hline ALIF & $120(3.6)$ \\
\hline Circumferential fusion & $1127(33.8)$ \\
\hline \multicolumn{2}{|l|}{ No. of fused levels } \\
\hline 1 & $2454(73.5)$ \\
\hline 2 & $843(25.3)$ \\
\hline 3 & $41(1.2)$ \\
\hline \multicolumn{2}{|l|}{ Inclusion of sacral vertebra } \\
\hline Yes & $1658(49.7)$ \\
\hline No & $1680(50.3)$ \\
\hline \multicolumn{2}{|l|}{ Laminectomy } \\
\hline No & $635(19)$ \\
\hline 1 level & $1940(58.2)$ \\
\hline 2 levels & $600(18)$ \\
\hline 3 and more levels & $163(4.8)$ \\
\hline
\end{tabular}

vision surgery for ASD in univariate models: age (linear HR 1.01, 95\% CI 1-1.02), initial spinal disease (DSPL: HR $2.1,95 \%$ CI $1.4-3.1 ; \mathrm{p}=0.0004)$, and including the $\mathrm{S}-1$ level in the fusion (HR 0.73, 95\% CI 0.54-0.98; $\mathrm{p}=0.037$ ). The other variables tested-sex, surgical fusion technique, number of levels fused, and if a laminectomy was neces- sary-were not significantly associated with the revision surgery for ASD (Table 2). In the multivariate regression model, only initial spinal disease affected the risk of ASD requiring surgery $(\mathrm{p}=0.0003)$. The highest risk was observed for DSPL (Fig. 2). Only initial spinal disease remained significant in the multivariate regression model, with DSPL being associated with the highest risk (HR 2.5, 95\% CI 1.5-4.1; $\mathrm{p}=0.0003$ ).

The number of patients still at risk (during follow-up) was $3270(98 \%), 2690(81 \%), 1490(45 \%)$, and $569(17 \%)$ at 2, 4, 6, and 8 years, respectively. The comparison of patients with $\leq 4$ years of follow-up showed slight discrepancies of little clinical relevance (Table 3). We found that significantly fewer patients with DSPL had the S-1 level fused $(22 \%$ [n $=364]$ of patients with S-1 fused vs $60 \%$ [n $=1010]$ without fusion).

\section{Discussion}

At 10 years of follow-up, about $25 \%$ of patients undergoing short lumbar fusion will develop ASD.$^{18}$ Although risk factors have been sought for the risk of clinical ASD, because of limitations of previous studies, we decided to conduct a large multicenter cohort study to identify variables associated with the risk of revision surgery.

In our study, only initial spine disease, and mainly DSPL, was independently associated with an increased risk for developing revision surgery. Indeed, the natural history of the degenerative spine appears to play an important role in the occurrence of ASD requiring surgery. This is consistent with previous reports. Previous studies have identified age greater than 60 years and having preexisting disc and facet degeneration on preoperative MRI of the segment above the fusion as risk factors for developing clinical ASD. ${ }^{1,10,14}$ Lee et al., in a retrospective series of 490 patients, also reported that ASD requiring surgery was more likely when patients were older than 60 years. ${ }^{15}$ In our study, age was identified as a predictor in the univariate model but not in the multivariate model. Therefore, we hypothesize that it is not age per se but more the degenerative status of the spine at the time of surgery that plays

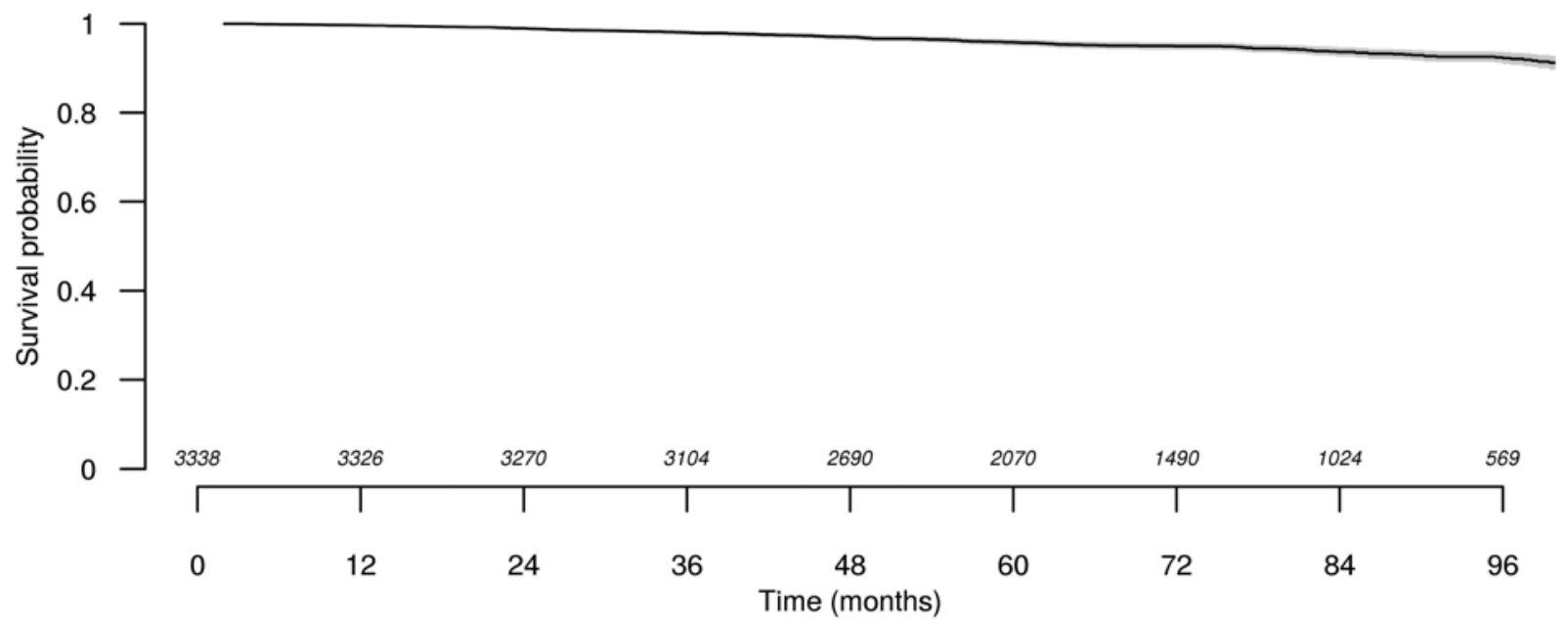

FIG. 1. Kaplan-Meier survival probability of not having revision surgery for ASD over time. The $95 \% \mathrm{Cl}$ is shown as the shaded area outside the line. 
TABLE 2. Prognostic factors of ASD requiring surgery

\begin{tabular}{|c|c|c|c|c|c|c|}
\hline \multirow[b]{2}{*}{ Variable } & \multicolumn{3}{|c|}{ Univariate } & \multicolumn{3}{|c|}{ Multivariate } \\
\hline & $\mathrm{HR}$ & $95 \% \mathrm{Cl}$ & p Value & HR & $95 \% \mathrm{Cl}$ & $\mathrm{p}$ Value \\
\hline Sex & 0.97 & $0.7-1.2$ & 0.85 & - & & \\
\hline Age (linear) & 1.01 & $1-1.02$ & 0.024 & 0.99 & $0.97-1$ & 0.13 \\
\hline Inclusion of the S-1 level in the fusion & 0.73 & $0.54-0.98$ & 0.037 & 0.95 & $0.7-1.3$ & 0.8 \\
\hline \multicolumn{7}{|l|}{ Fused level } \\
\hline 1 & 1 & $0.9-1.6$ & 0.29 & - & & \\
\hline$\geq 2$ & 1.2 & & & & & \\
\hline \multicolumn{7}{|l|}{ Initial spinal disease } \\
\hline DD & 1 & & & 1 & & \\
\hline DS & 0.99 & $0.54-1.8$ & 0.99 & 1.1 & $0.6-2.1$ & 0.7 \\
\hline DSPL & 2.1 & $1.4-3.1$ & 0.0004 & 2.5 & $1.5-4.1$ & 0.0003 \\
\hline SSPL & 0.9 & $0.5-1.5$ & 0.65 & 0.9 & $0.5-1.5$ & 0.7 \\
\hline Fusion type & & & & - & - & - \\
\hline ALIF & 1 & & & & & \\
\hline Posterolateral & 0.5 & $0.15-1.5$ & 0.21 & & & \\
\hline Circumferential & 0.97 & $0.7-1.3$ & 0.87 & & & \\
\hline Laminectomy & 1.3 & $0.85-1.9$ & 0.23 & & & \\
\hline Laminectomy above the fusion & 0.7 & $0.4-1.3$ & 0.3 & & & \\
\hline
\end{tabular}

a significant role in the occurrence of ASD. Moreover, radiographic progressions have already been reported of degenerative discal changes on MRI in patients suffering from low-back pain and older than 60 years of age who did not undergo surgery. ${ }^{2,6}$

The effect of the number of levels fused because of the risk of developing ASD remains debated. Sears et al., in a retrospective series of 912 patients, reported that patients with 3 or more levels fused had 3 times more risk of developing clinical ASD than those with fewer than 3 levels fused. ${ }^{18}$ In contrast, Ghiselli et al. ${ }^{7}$ in a retrospective series of 215 patients reported an increased risk of developing ASD in patients undergoing a single-level fusion compared with those having multiple levels fused. In the present study, we did not identify any association between the number of fused levels and ASD requiring surgery. Including S-1 in the fusion appears to prevent ASD in our univariate analysis. This is consistent with previous find- ings. For instance, Disch et al. ${ }^{5}$ reported that in contrast to floating fusions, fusions including the lumbosacral junction had a significantly lower risk for ASD in the cranial segment. However, in the multivariate regression, when both "S-1 fusion" and "degenerative spondylolisthesis" are included in the model, only DSPL remains significant. We therefore cross-tabulated "including the S-1 level in the fusion" and "initial spinal disease." We found that these 2 variables are strongly associated $(\mathrm{p}<0.0001)$. We can see that only $22 \%(n=364)$ of patients with $\mathrm{S}-1$ fused had the operation for DSPL, but it was 60\% $(n=1010)$ of patients without S-1 fused who required revision surgery. Therefore, the effect observed in the univariate model for $\mathrm{S}-1$ is accounted for by initial spinal disease. In the multivariate model, "including the S-1 level in the fusion" had no more effect. Additional laminectomy was not reported as an added risk for ASD requiring surgery in our study, unlike as some authors have reported. ${ }^{18}$

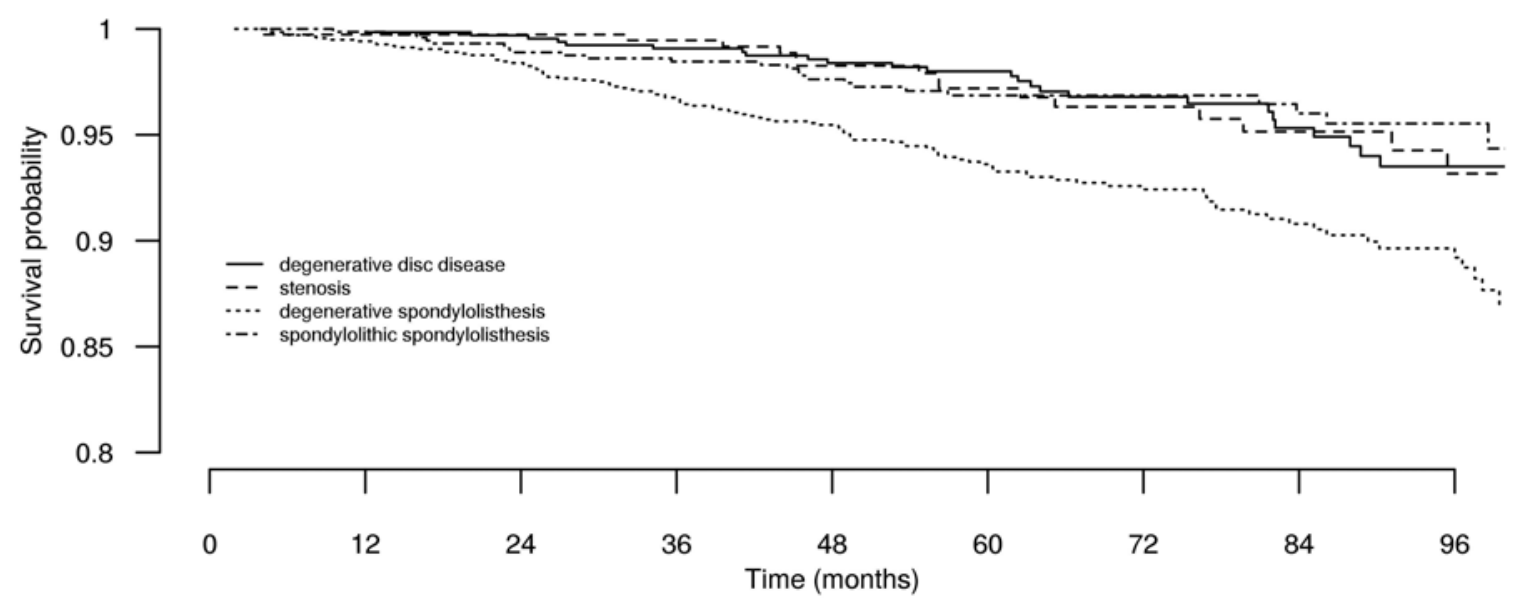

FIG. 2. Kaplan-Meier survival probability of not having revision surgery for ASD over time according to the initial spinal disease. 
TABLE 3. Demographic and surgical data comparison between patients with $>4$ years of follow-up and those with $\leq 4$ years of follow-up*

\begin{tabular}{|c|c|c|c|}
\hline \multirow[b]{2}{*}{ Characteristics } & \multicolumn{2}{|c|}{ Follow-Up (\%) } & \multirow[b]{2}{*}{ p Value } \\
\hline & $\leq 4 \mathrm{yrs}$ & $>4$ yrs & \\
\hline Mean age \pm SD (yrs) & $53.3 \pm 14.3$ & $51.2 \pm 14.6$ & $<0.001$ \\
\hline \multicolumn{4}{|l|}{ Sex } \\
\hline Female & $391(60)$ & $1517(56.5)$ & \multirow[t]{2}{*}{0.11} \\
\hline Male & $261(40)$ & $1169(43.5)$ & \\
\hline \multicolumn{4}{|l|}{ Initial spinal disease } \\
\hline $\mathrm{DD}$ & $100(15.3)$ & $554(20.5)$ & \multirow[t]{5}{*}{0.002} \\
\hline DS & $62(9.5)$ & $313(11.7)$ & \\
\hline DSPL & $284(43.6)$ & $1090(40.6)$ & \\
\hline SSPL & $168(25.8)$ & $558(20.8)$ & \\
\hline Other & $38(5.8)$ & $171(6.4)$ & \\
\hline \multicolumn{4}{|l|}{ Fusion type } \\
\hline Posterolateral fusion & $412(63.2)$ & $1679(62.5)$ & \multirow[t]{3}{*}{0.74} \\
\hline ALIF & $26(4)$ & $94(3.5)$ & \\
\hline Circumferential fusion & $214(32.8)$ & $913(34)$ & \\
\hline \multicolumn{4}{|l|}{ No. of fused levels } \\
\hline 1 & $483(74.1)$ & $1971(73.4)$ & \multirow[t]{2}{*}{0.75} \\
\hline$\geq 2$ & $169(25.9)$ & $715(26.6)$ & \\
\hline \multicolumn{4}{|c|}{ Inclusion of S-1 level in the fusion } \\
\hline Yes & $299(45.9)$ & $1359(50.6)$ & \multirow[t]{2}{*}{0.03} \\
\hline No & $353(54.1)$ & $1327(49.4)$ & \\
\hline \multicolumn{4}{|l|}{ Laminectomy } \\
\hline 1 level & $382(73.5)$ & $1558(71.4)$ & \multirow[t]{3}{*}{0.29} \\
\hline 2 levels & $103(19.8)$ & $497(22.8)$ & \\
\hline 3 and more levels & $35(6.7)$ & $128(5.9)$ & \\
\hline
\end{tabular}

Surgical fusion methods were recently reported as a risk factor of ASD requiring surgery. Lee et al. ${ }^{15}$ in a retrospective series of 490 patients, reported that patients who underwent posterior lumbar interbody fusion were 3.4 times more likely to develop ASD requiring surgery than those who underwent posterolateral fusion. ${ }^{15}$ Their hypothesis was that the use of an interbody device may increase segmental rigidity and increase stress transfer to the adjacent segment. ${ }^{19}$ In our series, the predominant fusion method was posterolateral fusion without an interbody device. This could explain why this variable was not associated with an increased risk in our series.

Our study has several limitations. First, because of the retrospective design of the study, patients may have been followed differently depending on their clinical status (attrition bias). However, we compared the characteristics of patients with different follow-up and did not find clinically important differences. Second, the primary outcome criterion was based on patient and surgeon decision, and there was no consensual indication for revision surgery. Despite revision surgery for clinical ASD having shown some benefits, ${ }^{3}$ revision surgery was the decision of the individual surgeon, and surgical indication for the adjacent segment could be different between 2 centers. However, all surgeons were experts and worked in high-volume centers, therefore limiting this bias.
Sagittal alignment after index surgery as a risk factor of ASD requiring surgery was not studied in our series. It has been suggested that sagittal alignment may contribute to adjacent-segment degeneration..$^{12}$ However, all patients were operated on by expert surgeons, and it is unlikely that they would have offered a short fusion in cases of lumbar or global malalignment. This large multicenter cohort study, however, allows important generalizability of the results.

\section{Conclusions}

Revision surgery for ASD was required in 5.6\% of patients 7 years after short lumbar spinal fusion. The only independent predictor of ASD in this large retrospective study was the initial spinal disease with an increased risk of 3.1 in cases of DSPL.

\section{References}

1. Ahn DK, Park HS, Choi DJ, Kim KS, Yang SJ: Survival and prognostic analysis of adjacent segments after spinal fusion. Clin Orthop Surg 2:140-147, 2010

2. Boden SD, Davis DO, Dina TS, Patronas NJ, Wiesel SW: Abnormal magnetic-resonance scans of the lumbar spine in asymptomatic subjects. A prospective investigation. J Bone Joint Surg Am 72:403-408, 1990 
3. Chou D, Dekutoski M, Hermsmeyer J, Norvell DC: The treatment of lumbar adjacent segment pathology after a previous lumbar surgery: a systematic review. Spine (Phila Pa 1976) 37 (22 Suppl):S180-S188, 2012

4. Deyo RA: Fusion surgery for lumbar degenerative disc disease: still more questions than answers. Spine J 15:272-274, 2015

5. Disch AC, Schmoelz W, Matziolis G, Schneider SV, Knop C, Putzier M: Higher risk of adjacent segment degeneration after floating fusions: long-term outcome after low lumbar spine fusions. J Spinal Disord Tech 21:79-85, 2008

6. Elfering A, Semmer N, Birkhofer D, Zanetti M, Hodler J, Boos N: Risk factors for lumbar disc degeneration: a 5-year prospective MRI study in asymptomatic individuals. Spine (Phila Pa 1976) 27:125-134, 2002

7. Ghiselli G, Wang JC, Bhatia NN, Hsu WK, Dawson EG: Adjacent segment degeneration in the lumbar spine. J Bone Joint Surg Am 86-A:1497-1503, 2004

8. Gillet P: The fate of the adjacent motion segments after lumbar fusion. J Spinal Disord Tech 16:338-345, 2003

9. Hilibrand AS, Robbins M: Adjacent segment degeneration and adjacent segment disease: the consequences of spinal fusion? Spine J 4 (6 Suppl):190S-194S, 2004

10. Kaito T, Hosono N, Mukai Y, Makino T, Fuji T, Yonenobu K: Induction of early degeneration of the adjacent segment after posterior lumbar interbody fusion by excessive distraction of lumbar disc space. J Neurosurg Spine 12:671-679, 2010

11. Kaplan E, Meier P: Nonparametric estimation from incomplete observations. J Am Stat Assoc 53:457-481, 1958

12. Kumar MN, Baklanov A, Chopin D: Correlation between sagittal plane changes and adjacent segment degeneration following lumbar spine fusion. Eur Spine J 10:314-319, 2001

13. Lawrence BD, Wang J, Arnold PM, Hermsmeyer J, Norvell DC, Brodke DS: Predicting the risk of adjacent segment pathology after lumbar fusion: a systematic review. Spine (Phila Pa 1976) 37 (22 Suppl):S123-S132, 2012

14. Lee CS, Hwang CJ, Lee SW, Ahn YJ, Kim YT, Lee DH, et al: Risk factors for adjacent segment disease after lumbar fusion. Eur Spine J 18:1637-1643, 2009

15. Lee JC, Kim Y, Soh JW, Shin BJ: Risk factors of adjacent segment disease requiring surgery after lumbar spinal fusion: comparison of posterior lumbar interbody fusion and posterolateral fusion. Spine (Phila Pa 1976) 39:E339-E345, 2014

16. Rajaee SS, Kanim LEA, Bae HW: National trends in revision spinal fusion in the USA: patient characteristics and complications. Bone Joint J 96-B:807-816, 2014

17. Sato S, Yagi M, Machida M, Yasuda A, Konomi T, Miyake A, et al: Reoperation rate and risk factors of elective spinal surgery for degenerative spondylolisthesis: minimum 5-year follow-up. Spine J 15:1536-1544, 2015

18. Sears WR, Sergides IG, Kazemi N, Smith M, White GJ, Osburg B: Incidence and prevalence of surgery at segments adjacent to a previous posterior lumbar arthrodesis. Spine $\mathbf{J}$ 11:11-20, 2011

19. Sudo H, Oda I, Abumi K, Ito M, Kotani Y, Minami A: Biomechanical study on the effect of five different lumbar reconstruction techniques on adjacent-level intradiscal pressure and lamina strain. J Neurosurg Spine 5:150-155, 2006

20. Xia XP, Chen HL, Cheng HB: Prevalence of adjacent segment degeneration after spine surgery: a systematic review and meta-analysis. Spine (Phila Pa 1976) 38:597-608, 2013

\section{Disclosures}

The authors report no conflict of interest concerning the materials or methods used in this study or the findings specified in this paper.

\section{Author Contributions}

Conception and design: Gillet, Guigui. Acquisition of data: Magrino. Analysis and interpretation of data: Scemama, Magrino. Drafting the article: Scemama. Critically revising the article: Gillet. Reviewed submitted version of manuscript: Guigui. Statistical analysis: Guigui.

\section{Correspondence}

Caroline Scemama, European Hospital Georges Pompidou, Reconstructive and Orthopaedic Surgery, 20 rue Leblanc, Paris 75015, France. email: scemamacaroline@gmail.com. 